\title{
Chapter 8 \\ From Projects to Processes to Implement Life Cycle Management in Business
}

\author{
Martin Baitz
}

\begin{abstract}
In general, companies start using a life cycle approach to manage the sustainability challenges and opportunities of their products through projects using life cycle assessment or other tools of the life cycle management toolbox like greenhouse gases accounting. As companies gain experience the way they manage the life cycle of their products matures, it becomes less about implementing projects and more about putting in place organization-wide procedures. The latter allow companies to address systematically the identified business challenges and opportunities of their whole portfolio or at least their key products with much less effort than carrying out multiple individual projects.
\end{abstract}

Keywords Life cycle assessment (LCA) - Life cycle management (LCM) • Sustainability $\bullet$ Process integration

\section{A Brief History of Life Cycle Approaches}

In the beginning of a new thinking some aspects dominated the discussion. Energy in the way it is technically used so far - is limited and environmental impacts can be a threat, if ignored. As the supply chain has to cooperate to solve (economic and technical) tasks and harvest its opportunity, it was quite evident environmental aspects needed a supply chain approach as well.

Life cycle thinking (LCT) was borne in the 1980s. In the 1990s, scientific bodies like SETAC (Society of Environmental Toxicology and Chemistry) recognized a need to draft rules to harmonize the new way of thinking, calculating and analyzing products systems in a way that international cooperation and exchange is fostered. This "Code of Practice" (Consoli et al. 1993) may be understood as an important yardstick to turn thinking into doing.

M. Baitz $(\bowtie)$

thinkstep AG, Hauptstraße 111-113, 70771 Leinfelden-Echterdingen, Germany

e-mail: martin.baitz@thinkstep.com 
Life cycle assessment (LCA) was about to be borne (Fava et al. 1990) and became an international standard under ISO in 1997 (ISO 14040: 1997). Building on this new standard industry, research and academia was able to use this method in a consistent way. Due to differences in goal and scope between stakeholders the interpretation of the systems and the results can be different; however keeping to ISO ensures that the differences remain understandable and interpretable. This empowers consumers or users of information to check against their own (technical, political or private) motivations and boundaries. The method remains consistent and transparent. The possibilities within this new assessment method reached beyond engineers and scientists. The call to consistently measure, control and target against life cycle results combined with related communication measures lead to a further evolution.

Life cycle management (LCM) developed from a professional interpretation and decision with the help of life cycle assessment. For most professional users of life cycle based sustainability approaches in industry, these three evolutionary steps belong together. LCT is the required mindset, LCA the method and LCM the process.

\subsection{From Pioneers to Industry Standards}

There are many individuals mentioned if talking about scientific or societal thought leaders in life cycle aspects and the roots of sustainability. However, thoughts stay basically fictional until they are applied and measurable.

Pioneer companies like, e.g., Volkswagen, Daimler, Renault, BASF, DOW, Wacker, ThyssenKrupp, and Amcor recognized quite early on the necessity and opportunity to apply the topic in a professional manner using a standardized method, related software tools, a blend of own in-house data, specific supplier data, realistic upstream data and justified background data.

During the 1990s, pioneer companies and organizations pace their way towards international standards. Without these pioneers, LCM probably would not have (or at least significantly later) matured into applied LCA about two decades ago (see also Hunkeler et al. 2004).

\subsection{From Trial to Maturity}

After the international standards were in force, the number of studies with questionable claims decreased, whereas the number of studies with reasonable results increased. Most likely due to better identification of unjustified claims. Reducing the arbitrary application of the method, combined with clear rules, described life cycle assessment being implemented in a number of companies and organizations in the mid-1990s to early 2000s to drive product innovation. 
Even having now the standards and related reviewers available, some stakeholders or believers in specific schools of thought still pretend today LCA is arbitrary: However, in most cases the preferred method of these critics are completely nonstandardized and sometimes even their private invention. Even more astonishing, the most arbitrary results originated rather not from industry, maybe because of self-protection.

However, refocusing on the important aspects, it may be summarized that LCA took its chance to mature from scientific into professional applications in industrial organizations, while some non-standardized approaches, some experimental databases and trial software disappeared.

\section{From Project to Process}

LCA is recognized as the best available methodology to investigate environmental sustainability performance in a reliable and transparent way and for communication, along the value chain and throughout one's own organization; to support and help to cross-check development and strategic decisions. LCA in practice must be time, cost and resource efficient. LCA results and the underlying data are only the basis for communication and decision making and are to be converted into a technical conclusion, the nature of which is determined by the recipient of the result (e.g., product engineers, executive management, marketing, suppliers, or consumers). LCA is applied for quantitative environmental management and should reflect the industrial reality adequately. This sounds trivial, but often enough data and modelling approaches are used to produce results, which have a goal and scope that is not suitable for decision support. Benchmarking one's own processes and products against the competition - commonly on a cost basis - is a common practice in industry. Evaluation of the results within the competitive landscape is needed to take suitable decision for your own optimization approach. Aside from the internal use of LCA as an internal planning tool, another potential lies in connecting partners along the value chain. By collaborating on an LCA, suppliers and customers strengthen their relationship, gain valuable insights in markets and their success factors, and enhance an overall exchange of experiences. This fosters innovation. LCA is a business imperative today. Therefore successful LCA application is the main aim in industry (Baitz et al. 2012a).

As described earlier (Baitz et. al. 2012b), the topic of LCA needs proper implementation in the companies: It must be manageable. Management of tasks basically calls for two main aspects: measurable information and properly installed processes. What gets measured gets managed.

Proper management of life cycle aspects needs a shift in the mindset: From project thinking towards process thinking. Alignment of methods, data and communication throughout the company is an important step. But why restrict the degree of freedom in doing LCA in companies? Simply to gain quality of results, harvest the 
full potential of aligned application, communication of LCA results and to be able to measure company targets against consistent actuals.

Companies realize that an extended use of LCA can foster value creation, if implemented as part of a professional management process.

In (Baitz et. al. 2014) it is discussed that successful companies basically create value through sustainability in four discrete ways:

- In sales over increasing market share or new market entry by quantifying of benefits B2B or B2C or by promoting innovation and new products based on solid facts.

- Through cost reduction due to increase of value chain and operational efficiency as well as employee productivity.

- Risk mitigation like operational risk management or regulatory management which supports business continuity.

- The brand value is increased due to reputation as well as employee attraction and retention, which lowers new employee hiring costs.

To generate value on sustainability in a company, a platform combining IT technology (software and data exchange systems), content (adequate databases) and a positive user experience is key. The positive user experience is most efficiently implemented by an adequate and balanced share of technology and service support.

In sequence, companies want to determine more quickly what the social, environmental and economic tradeoffs of their products are (screening)? How they can provide more value by combining multiple data sources (scoping)? And how the companies may integrate sustainability management with existing management systems, such as ERP, PLM, CAD or supply chain management (scale)?

Along this approach of "Screen, Scope, Scale" many companies identify their specific pathways, then grow their project phase and finally begin to prepare an evolutionary step towards process implementation.

\subsection{Screening to Identify Pathway}

Under the umbrella "innovation with sustainability" different topics exist that companies want or already need to cover; ideally with an integrated approach. The importance of the topics are related to the specific situation of the company. No matter what a company already does, it is valuable to build on existing activities and to get in-house people to support the "pathfinder mission".

Under the headline "innovation and cleantech" some companies do sustainability research and development, external research funding, product stewardship and sustainability solution marketing. In strategic energy management often e.g., office energy management, IT/telecoms energy management, industrial energy management, 
on-site renewable energy and energy management systems get clustered. Sustainable supply chains need to be managed e.g., retail or supply chain energy management or aspects of supply chain transparency.

Environmental performance has long been an important aspect in the companies' sustainability approaches including environmental remediation, occupational health and safety, pollution control and prevention, biodiversity and land stewardship, and waste water and water management.

Most of the above mentioned topics are done in pure project style. Some companies started different projects with direct links to individual tasks and needs that needed to be addressed. This might be tasks concerning suppliers, customers, cooperating industries or from governmental bodies or their own research and development topics.

Some companies selected so-called lighthouse projects on especially important topics to gain insights on intercompany cooperation while ensuring that the results are valuable for the company to guarantee a wide range of company stakeholders from project engineer to executive management are interested in the results. The selection of lighthouse project topics can be done monetarily (important revenue stream) or by image (specific product with specific message) or by any other company-relevant aspects.

However, some companies prefer to start with non-critical trial projects to test the approach through a shadow-project in a protected internal environment without any information exchange with suppliers, customers or the public on data gathering and results communication.

Typically in the screening phase the four aspects - materiality, practicability, quality and transparency - are addressed in a company specific way:

- Under materiality questions are answered like: Which data do I have? Which data is relevant for me?

- Practicability addresses questions like: Where do I get my company data and my supplier data from? Where do I get reliable background data?

- Concerning quality companies answer questions like: What does quality mean in my business? What are relevant quality indicators for my goal?

- Transparency in professional applications means: Are processes documented and change monitored? Are routines qualified and auditable?

In the screening phase companies start with initial workshops to clearly scope the work and define the goal. In most cases the first is step is to benchmark against the average in the industry. In a materiality assessment the inventory situation of in house data is checked and assessed. Life cycle based product and corporate environmental draft footprints are often a first screening result.

An example of doing a successful screening is a US based company which design and manufacture floors and ceilings for residential and commercial products. Their challenge was losing market share in an industry, where sustainability is a defining strategy. The solution was life cycle assessment showing the quantifiable and relevant 
savings of water, virgin material and electricity, supported by senior leadership to reach corporate awareness. The business value was cost reduction, brand enhancement, improved business environment as well as top line revenue growth.

Another example is a city development in the United Arab Emirates designed to rely on solar energy and other renewable energy sources. The goals are to monitor embodied carbon in supply chain and construction to achieve a "carbon neutral" goal of $475 \mathrm{~g} / \mathrm{m}^{2}$ and to set up a database of sustainable building processes and materials. Features are to produce environmental product declarations (EPDs) and carbon footprints, linked to a city portal and consistently setting targets, benchmarking and monitoring the performance. Main outcomes here is decisionmaking support e.g. in the progress of building completion vs. total carbon emissions to date.

A third example of a value adding screening phase activity is a national dairy service acting as a body for dairy farmers and the industry to help farmers adapt to a changing operating environment, and achieve a profitable, sustainable dairy industry. The challenge was to establish the industry's carbon footprint, from farm to a representative national dairy product. Further to generate a reliable basis for product carbon footprinting and environmental labelling. The solution was a web-based data collection and integrated analysis approach. The benefit are verifiable greenhouse gas footprints at industry level and an auditable and expandable platform reporting solution leading to customized greenhouse gas footprints for individual farmers.

\subsection{Scoping to Grow Project Phase}

After successful screening of the company specific pathway, the companies typically aim to merge many environmental and social topics under one common umbrella of life cycle based sustainability approaches.

Related ISO standards are in most cases the solid basis of environmental related work in companies. The companies' data foundation - consisting of in-house and own site data, specific supplier data, representative generic upstream and downstream data as well as background data - typically evolved and grew from the starter projects.

In the scoping phase the companies evaluate the magnitude and impact that can be reached within their given goal and scope.

The pathway successful companies follow is in principle comparable or often even identical. However, the speed and the needed measures differ and are specific to each company. Competency and persistence of the person in charge of the topic are decisive. However the most important differentiator is if a dedicated in-house team - dealing more or less exclusively with the topic - is available in the respective company or not. Without a dedicated in-house team the chances to succeed are equal, just the measures to reach it are different. 
In-house teams are a huge knowledge pool and can work on sensitive aspects without any external interference, which is an asset for any company. However, depending on the company structure in-house teams can be quite expensive. Working with no dedicated in-house team might be cheaper and easier to manage, as the content and deadline responsibility is managed by a contractor. However, the quality of the contactors work is decisive for the quality of the companies end results.

It might be fair to say that in most of the successful companies in this topic established dedicated in-house teams along their journey in the topic and can work in many or most cases fairly independent from external consultant companies or experts.

The beauty of the topic is that businesses can define their own journey and mile stones towards sustainable success. No entry hurdle, no rush, no "point of no return" decisions in the process are necessary.

A successful sustainability approach simply means, to build on existing measures, to use as much as possible existing in-house information and to choose a professional software and data solution to create multiple (business) benefits from the approach.

Summarizing the scoping phase is characterized by (company and external) stakeholder engagement often with strategy workshops to align on strategy development and implementation, identification of suitable corporate reporting software solutions of, e.g., GRI (Global Reporting Initiative), Carbon, EH\&S (Environment, Health, Safety), or Building Portfolios. Further LCAs and organisational environmental footprints are undertaken and Environmental Product Declarations (EPD) done. The growing data and resulting demand calls for professional product sustainability software solutions.

An example doing successful scoping is a German financial institution. They decided to solve the topic with and ISO 14001 compliant environmental management system. The idea was central sustainability performance management. Their aim was to quantify the sustainability performance. They reached reduced electricity consumption of $€ 111,000$ /year alongside with $29 \%$ reduction in paper consumption, which equals $207 \mathrm{t}$. The gained business value was a total resource cost reduction of $€ 300,000$ in 6 months and total cost reduction of another $€ 500,000$ in the second year. Additional business value was reputation and brand enhancement.

Another example is an American multinational consumer goods company. Their defined goal was to integrate a product sustainability software tool that anyone in the organization could use. Boundary conditions were that no new hires were needed and that the staff did not need training on the product sustainability software tool. The solution was an LCA solution allowing product designers to understand the environmental impacts and deliver results of a proposed modification in less than 15 min. Further benefits were achieved by integrating the solution fully into the product design community. 
A third example of successful scoping is from a German specialty chemical company. Very early the leading heads of the initiative recognized the goal of the endeavour must be to turn LCA from a project based business into something embedded into the core processes of the company to avoid implementation risks of new products or processes. The solution was to focus on dedicated and relevant products and projects with the support of an in-house team. This led to instant knowledge transfer to the companies' sustainability team. This was achieved with professional software and database solution and ad hoc on-demand consulting supplemented from the external partner. The benefits are extensively and reliably used and communicated LCA information throughout the company. The LCA group also experienced extraordinary internal and external visibility and success.

\subsection{Scaling to Prepare Process Phase}

After successful scoping, the company aims to scale the approach according to their specific product or business strategy. Appropriate communication of facts based on one core life cycle information system is essential. C-level, engineering department heads as well as research engineers need tailored communication packages based on the same facts and data.

Therefore software and database management and maintenance ideally moves into the core of the activity. Foreground data management and in-house data collection needs to be consistent with supplier data collection and integration as well as background data management. Data updates from the background data supplier and distribution of their own company data to subsidiaries is organized including quality assurance routines. Leading companies start to organize their work by client-server based team work approaches. To harvest information synergies similar activities are combined under one common umbrella of a life cycle based sustainability approach, incorporating corporate sustainability activities as well as compliance and material information topics.

Integration and automation is a core topic if companies aim to scale their life cycle based sustainability activities. Automated LCA generation using existing information like e.g. "bill-of-materials (BOM)" or recipe lists is another area where leading companies are scaling the process towards higher quality in less time. Linking to ERP systems and available in-house data systems is also a promising step in scaling. The scaling phase increasingly enables integrated monetary assessments, with approaches like life cycle costing (LCC) and environmental costing approaches (e.g. Trucost) along with options to quantify or evaluate social aspects.

Summarizing, it can be said that in the scaling phase enterprise sustainability performance software (GRI, Energy \& Carbon, EH\&S, supply chain, building portfolios), management systems (EMAS, ISO 14001/50001), product sustainability performance software (LCA, EPD, PEF, Eco-Design), EPD and LCA automation as well as PLM-integrated materials compliance management is most effective when 
operated over one integrated platform to gain maximum from synergy and consistency and to reduce risks from data gaps and inappropriate data.

An example of successful scaling is with an American multinational confectionery, food and beverage enterprise that had a challenge to understand the environmental impacts for products and packaging. The aim was to improve process efficiently and examine new promising technology. The solution was to conduct LCAs for core food products and to establish a professional LCA in-house team. Alongside these activities an extensive database of in-house process data as well as external upstream and background data was partly set up and partly bought on demand. The measures incorporated sustainability into many of its existing and new products. The business value was the company is able to select the best alternative with regards to economic and environmental aspects before finalizing a new product design. This includes the quantification of incorporated costs in analysis to realize savings.

Another example again with an American multinational, this time an information technology corporation. The challenge here was increased customer demand for environmentally preferable and professionally registered products. Further, and inevitably, the need for LCA-backed information to guide product development teams. A further challenge was the complex supply chains. The solution was a LCA platform with pre-configured LCA templates to allow to scale and run over 70 LCAs on their portfolio using an LCA solution. The business value was that the LCA platform realized savings of over USD $\$ 1$ million and hundreds of hours of time. A further business value is the increased efficiency and the ease of registering products within the assessment standard. This means in the end a faster market access to maintain a competitive advantage.

Another example, this time a German automobile manufacturer needed its existing and new products to comply with legislations such as the EU Directive 2005/64/EC on the recyclability of motor vehicles. The company applied professional software and extensive data sets to analyze vehicle components in terms of their recyclability. Scenario calculations allowed the consideration and comparison of different material options, and to improve favourable options. For example, different front module concepts were compared and material options like steel, aluminium-steel, plasticsteel assessed. The analysis revealed different strengths of the concepts concerning primary energy demand, weight and recycling. Scenario calculation showed improvement potentials which have been applied accordingly. The business value is combined compliance and improvement.

Another German automobile manufacturer also achieved success with international production sites and brands. The challenge was to perform an LCA of every new vehicle already in the design phase, to be able to grasp and execute on design options and optimization potentials. The goal was to combine design for environment with marketing and communication. The solution was a software implementation and corresponding BOM import for efficient LCA work. The benefit is the automobile manufacturer now optimizes cost and environmental impact of cars already during product development. 


\section{From Process Integration to Sustainable Supply Chain and Product Management}

Companies that successfully embedded life cycle approaches in business processes have increased the business value of sustainability. According to our approach, companies run through a maturity curve (Fig. 8.1), with more or less external support. To enhance stepwise success and business value with sustainability the maturity curve can be entered at any point. Importantly it is not where a company starts, but to know the pathway and the next step. Solutions are needed that are able to bring a company efficiently further without expensive rework or duplicating effort.

IT solutions are key to drive the value of sustainability approaches. Merging sustainability aspects, compliance aspects and supply chain aspects under one platform approach is most promising.

Data is the foundation. Actuals as well as targets are important. The business value must be very clear: top line, bottom line and risks involved. Sustainability must be executed; a tangible example is the approach presented: screen, scope, scale. It is important to converge organization and product performance. Therefore it is important to combine materials compliance, risk and sustainability management. Collaboration is important; not only internal, but also to stakeholders, the supply chain and customers. Design for sustainability must be done early and must be solved upstream, not downstream.

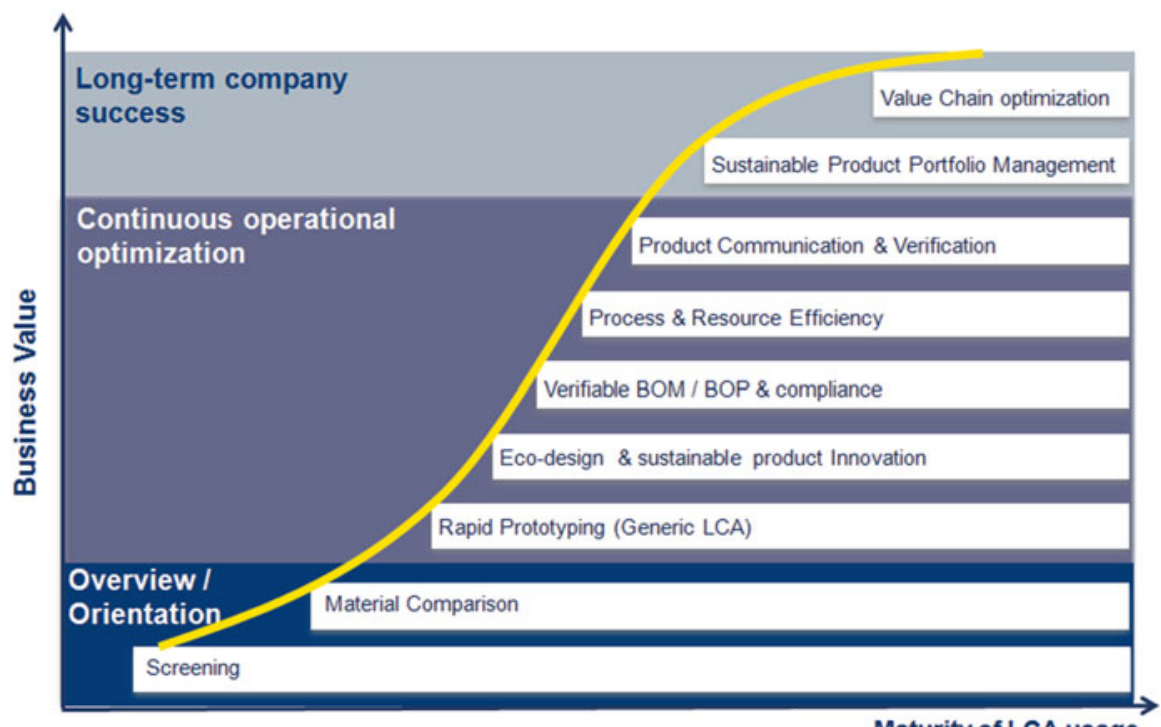

Fig. 8.1 The maturity curve of increasing business value 


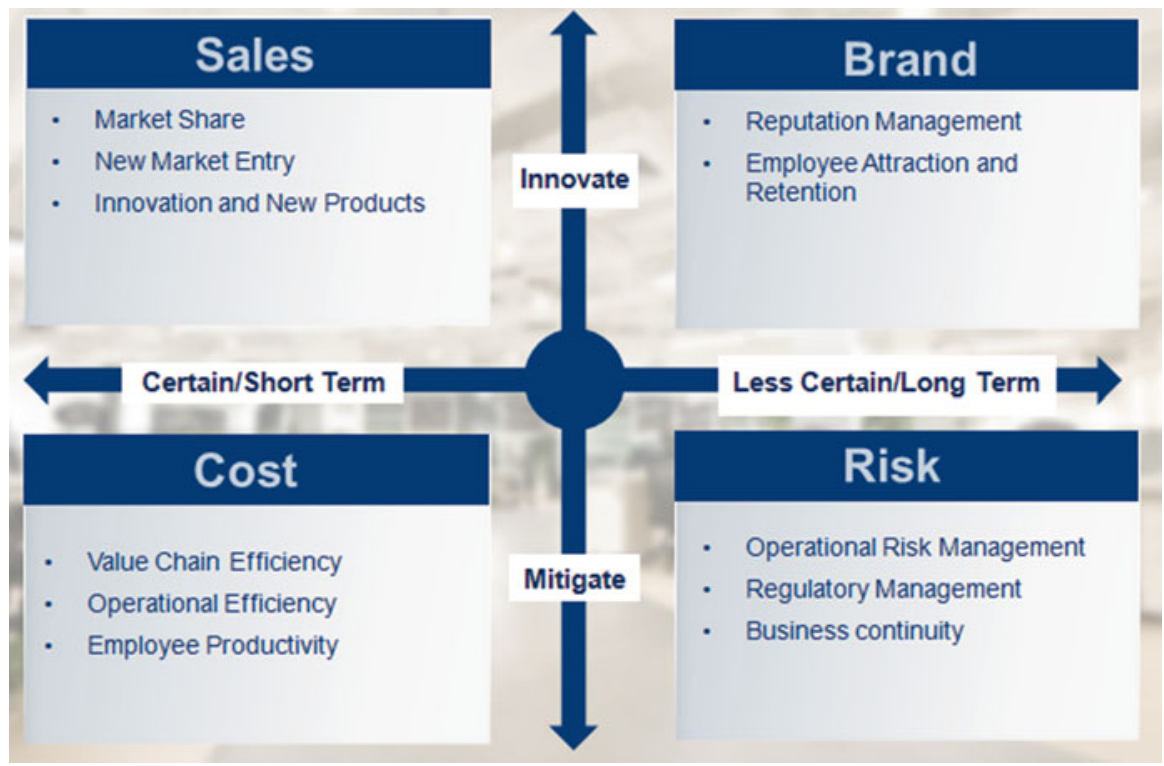

Fig. 8.2 Business value of sustainability

Life cycle related sustainability solutions are able to increase sales, improve the brand and reduce costs and risks, if these are integrated in business processes to do sustainable supply chain and product management of long-term and short term aspects of innovation and mitigation (Fig. 8.2).

Companies can rather freely decide where to start their journey and if they solve the topic in-house or with external support. However a suitable and smart IT and database solution is in any case indispensable.

Open Access This chapter is distributed under the terms of the Creative Commons Attribution Noncommercial License, which permits any noncommercial use, distribution, and reproduction in any medium, provided the original author(s) and source are credited.

\section{References}

Baitz M, Osumi M, Yukiyoshi H, Florin H (2012a) Symbiosis of science and application - LCA as business case. Ecobalance conference, Yokohama

Baitz M, Albrecht S, Brauner E, Broadben C, Castellan G, Conrath P, Fava J, Finkbeiner M, Fischer M, Fullana i Palmer P, Krinke S, Leroy C, Loebel C, McKeown P, Mersiowsky I, Möginger B, Pfaadt M, Rebitzer G, Rother E, Ruhland K, Schanssema A, Tikana L (2012b) LCA's theory and practice: like ebony and ivory living in perfect harmony? Int J Life Cycle Assess. doi:10.1007/s11367-012-0476-x

Baitz M, Osumi M, Yukiyoshi H, Florin H (2014) Life cycle based sustainability solutions: how successful companies turn sustainability solutions into company benefit and business value. Ecobalance conference, Tsukuba 
Consoli F, Allen D, Boustead I, Fava J, Franklin W, Jensen AA, de Oude N, Parrish R, Perriman R, Postlethwaite D, Quay B, Séguin J, Vigon B (eds) (1993) Guidelines for life-cycle assessment: a 'code of practice', 1st edn. From the SETAC workshop held at Sesimbra, SETAC, Pensacola, 31 Mar-3 Apr 1993

Fava JA, Denison R, Jones B, Curran MA, Vigon B, Selke S, Barnum J (eds) (1991) SETAC workshop report: a technical framework for life-cycle assessment. Smugglers Notch, Vermont, SETAC, Washington, DC, 18-23 Aug 1990

Hunkeler D, Saur K, Rebitzer G, Finkbeiner M, Schmidt WP, Jensen AA, Stranddorf H, Christiansen K (2004) Life-cycle management. SETAC, Pensacola. ISBN 1-880611-77-5

ISO 14040 (1997) Environmental management - life cycle assessment - principles and framework. Geneva 